\author{
Aneta Lorek and Maciej Paczuski
}

\title{
STUDIES ON SEDIMENTATION OF ASPHALTENE DEPOSITS IN DISTILLATION RESIDUES
}

\author{
Faculty of Civil Engineering, M echanics and Petrochemistry, Institute of Chemistry, \\ Warsaw University of Technology, Lukasiewicza 17, 09-400 Plock, Poland
}

a.Iorek@pw.plock.pl

Received: October 12, 2007

\begin{abstract}
Experimental methods used for the evaluation of stability of solids in liquids dispersions, are presented in this work. Modern analytical techniques, such as tensiometry, scanning and static turbidimetry, have been applied for the characterization of dispersion components. The influence of selected surface active substances on the dispersion stability has been demonstrated.
\end{abstract}

Key words: dispersion, surface properties, stability, vacuum residue

\section{Introduction}

An increased interest in the processes of conversion of petroleum vacuum distillation residue is a consequence of an increase of engine fuels consumption, as well as new trends in quality of fuels and petroleum products and more restrictive ecological regulations. Vacuum residue hydrocracking (H-Oil process) is one of such processes. It is a modern, high-pressure and high-temperature technology of hydrodesulphurization and hydrodemetallization. H-Oil technology enables significant deepening of crude oil conversion to fuels and production of low-sulphur heating oil. This process was designed by HRI and for the first time applied at industrial scale in 1963 at Cities Service Lake Charles refinery, Louisiana, USA.

In Poland, Vacuum Residue Hydrodesulphurization (HOG) installation was launched in 1999 at PKN Orlen S.A. refinery as the fifth unit in the world operating on the basis of H-Oil technology. The feeds of this process are: petroleum vacuum distillation residue and hydrogen gas.

The process is carried out at the temperature of $695 \mathrm{~K}$ and hydrogen gas pressure of $18 \mathrm{MPa}$. Installation with design capacity of 1.8 million tones of vacuum residue per year was designed to operate in two regimes of conversion of heavy components to components boiling at the temperatures below $811 \mathrm{~K}: 52 \%$ and $66 \%$. From the beginning, the first alternative is realized. In the industrial H-Oil technology, ebullient catalytic bed is utilized, being a unique feature of these processes. Ebulliency is a process of fluidization of catalyst particles in a reactor, induced by an adequate flow of the mixture of liquid and gaseous feed. Catalyst bed is carried up by continuous movement of liquid and gaseous product from the bottom of the reactor upwards. Random movement of catalyst particles in the ebullient bed results in adequately mixing in the whole volume. Liquefied petroleum gas, stabilized gasoline, fuel oil, light and heavy vacuum oil, low sulphur (ca. $1 \mathrm{wt} \%$ ) hydrodesulphurized vacuum residue are products of this process.

Table 1

Selected properties of crude oil vacuum residue and hydrodesulphurized vacuum residue

\begin{tabular}{|l|c|c|c|}
\hline \multirow{2}{*}{ Parameter } & \multirow{2}{*}{ Unit } & Stock & Product \\
\cline { 3 - 4 } & $\mathrm{kg} / \mathrm{m}^{3}$ & 991 & 1012 \\
\hline Density & wt \% & 2.62 & 1.17 \\
\hline $\begin{array}{l}\text { Concentration of } \\
\text { sulphur }\end{array}$ & wt \% & 4.97 & 5.14 \\
\hline $\begin{array}{l}\text { Substances insoluble in } \\
n \text {-heptane }\end{array}$ & wt \% & 0.02 & 0.14 \\
\hline $\begin{array}{l}\text { Substances insoluble in } \\
\text { toluene }\end{array}$ & wt \% & 0.05 & 22.6 \\
\hline Coking residue & & & \\
\hline
\end{tabular}

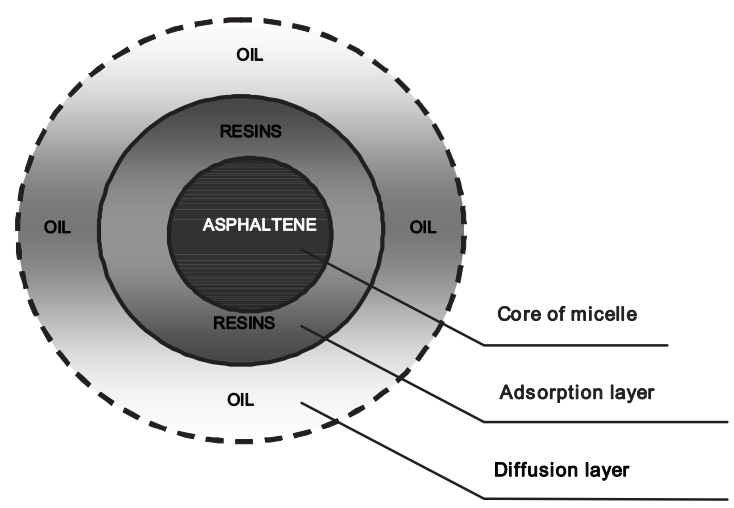

Fig. 1. Vacuum residue as dispersion 
From the beginning of the operation of $\mathrm{HOG}$ installation there were problems have been appearing related to the occurrence of residues in the products and installation equipment.

Vacuum residue from the process of vacuum residue hydrodesulphurization is an unstable dispersive system in which dispersed phase is constituted of asphaltene micelles stabilized with petroleum resins.

In the reactors of $\mathrm{HOG}$ installation petroleum resins are converted at higher efficiency than asphaltenes. The change of chemical composition results in the destabilization of the system (Fig. 2).

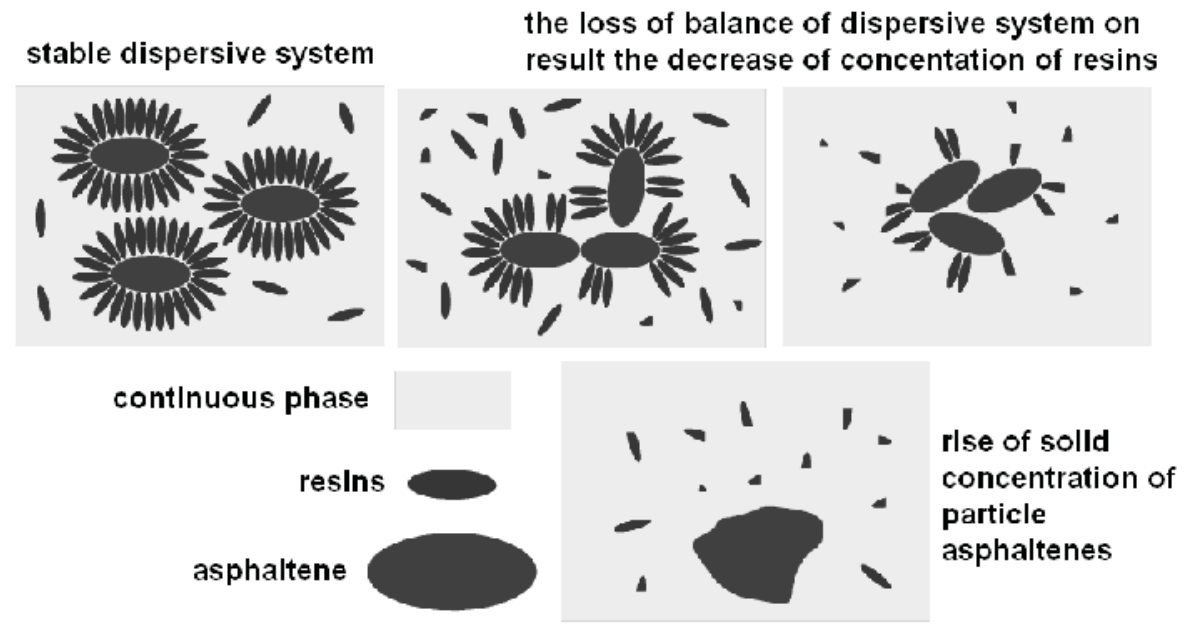

Fig. 2. Destabilization of dispersive system by the change of chemical composition [1]

Operational problems, accompanying the conversion of vacuum residue are related to the presence of sulphur, nitrogen, oxygen and heavy metal compounds, as well as coke precursors in the feed. Significant operational problems are also caused by the residues precipitating from the post-reaction mixture in the process. The deposits are formed on the walls of pipelines and other apparatus - separators and heat exchangers, sometimes causing clogging of pipelines and valves. The factors influencing the deposits formation in the Vacuum Residue Hydrodesulphurization installation are:

- feed properties;

- use of vacuum column recycle;

- carrying off catalyst particles by the stream leaving the reactor;

- electrokinetic effect.

In the development of H-Oil technology the attempts to modify the process in order to reduce deposits formation in the products have been undertaken. In order to achieve this goal, such methods as diluting the feed with highly aromatic diluent, improving the catalyst, introduction of surface active additives have been applied [1-3].

The studies on the reduction of formation and sedimentation of deposits in desulphurized vacuum residue - HOG installation product, are being carried out for several years in the Institute of Chemistry of Warsaw University of Technology in Plock, . Characterization of asphaltene dispersions and studies on the effectivity of dispersants are realized basing on modern research techniques, such as:
- tensiometry studies, used to study the compatibility of dispersion system components, basing on the surface properties and effectivity of additives surface active substances;

- turbidimetric studies, for the estimation of flocculation point of asphaltenes in desulphurized vacuum residue solutions and the influence of dispersants on the phase stability of the dispersion;

- sedimentation studies, according to the test elaborated by Octel, in the solution of desulphurized vacuum residue and modified with surface active substances $[4,5]$.

\section{Experimental}

\subsection{Materials}

Samples of hydrodesulphurized vacuum residue were collected from the Vacuum Residue Desulphurization (HOG) installation at PKN Orlen S.A. refinery in Plock. The samples were collected during stable operation of the installation. For the investigations $10 \mathrm{wt} \%$ solutions of desulphurized vacuum residue in toluene were prepared.

Auxiliary substances:

- toluene, analytically pure;

- $n$-heptane, analytically pure;

- chloroform, analytically pure;

- petroleum ether.

For the purification of deposits and preparation of additive solutions, petroleum ether produced by PKN Orlen 


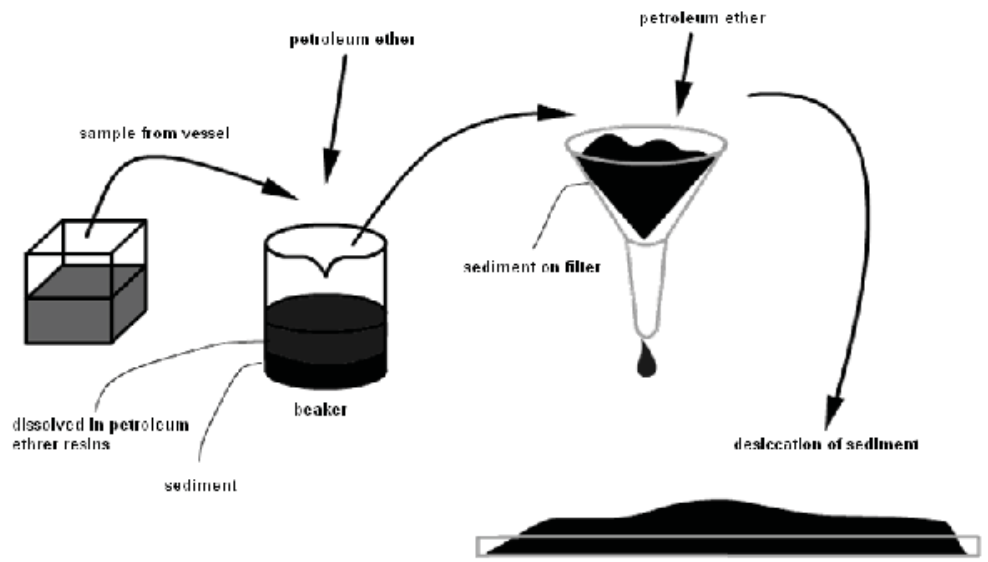

Fig. 3. Preparation diagram of samples of powdered asphaltene deposits

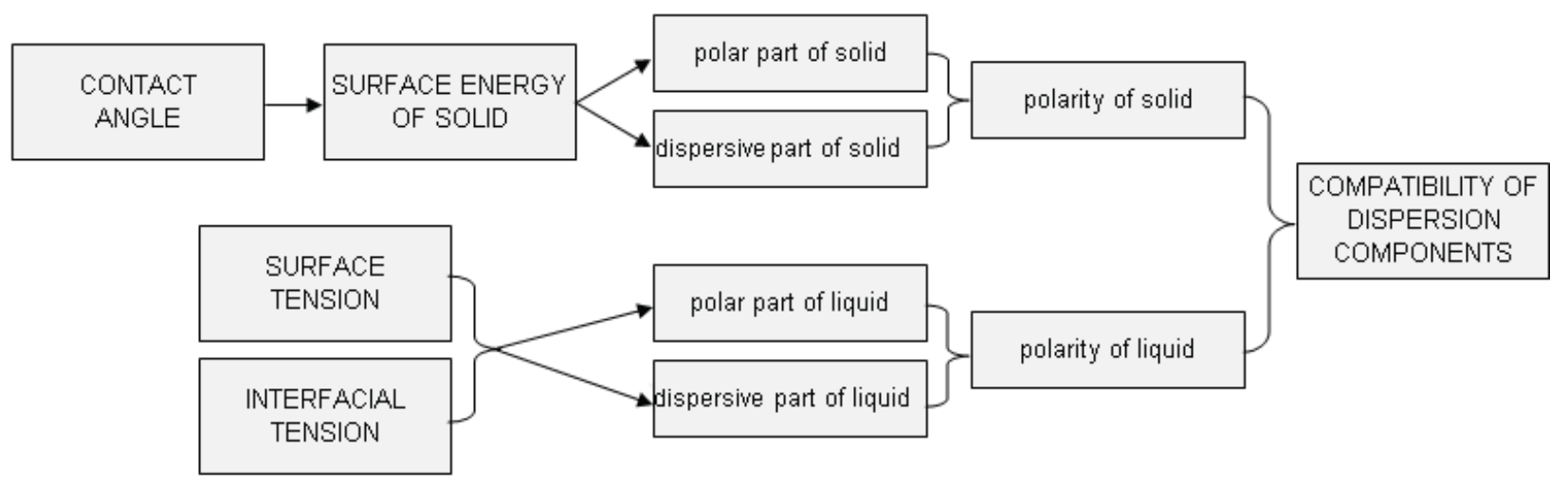

Fig. 4. Diagram of determination of dispersion components compatibility

in Plock, has been used. Reagents were used without any further purification.

Additives:

A - mixture of alkylbenzenesulfonic acids;

$\mathrm{H}$ - block copolymer of acrylamide and acrylic acid;

$\mathrm{K}$ - composition of phenolic resins;

$\mathrm{Z}$ - polyoxyalkylamine derivative.

Additives were used in 100 and 1000 ppm wt. concentrations.

\subsection{Compatibility of dispersion components based on the surface properties (contact angle, surface energy, surface tension and interfacial tension)}

Surface properties were determined using Krüss K 100 tensiometer.

\subsubsection{Contact angle measurements of powdered solids}

The instrument enables the measurement of contact angle of powdered porous solids according to Washburn method. For determination of the contact angle it is necessary to estimate the capillary constant of a studied solid. Measurements of sorption kinetics of liquid of known density, viscosity and surface tension were carried out for this estimation. $N$-heptane was used as a standard liquid for the measurement of capillary constant because of having a low surface tension and advancing contact angle (for any solid it is close to $273 \mathrm{~K}$.)

For the calculations of capillary constant the Washburn equation [7] was used for instrument's software:

$$
\frac{l^{2}}{t}=\frac{(c \cdot r) \cdot \sigma_{1} \cdot \cos \theta}{2 \eta}
$$

where 1 - flow front; $t$ - flow time; $r$ - capillary radius; $c$ - capillary constant; $\eta$ - viscosity of the liquid; $\theta$ - advancing angle; $\sigma_{I}$ - surface tension of liquid.

In this work for the determination of contact angles we use liquids with different polar components of surface tension. 
Properties of liquids used for determination of contact angles [internal database of tensiometer software]

\begin{tabular}{|l|c|c|c|c|c|}
\hline \multirow{2}{*}{ Liquid } & Density & Viscosity & Surface tension & Dispersive Part & Polar Part \\
\cline { 2 - 6 } & $\mathrm{kg} / \mathrm{m}^{3}$ & $\mathrm{mPa} s$ & $\mathrm{mN} / \mathrm{m}$ & $\mathrm{mN} / \mathrm{m}$ & $\mathrm{mN} / \mathrm{m}$ \\
\hline Water & 997 & 0.995 & 72.30 & 18.70 & 53.60 \\
\hline Chloroform & 1483 & 0.568 & 27.15 & 27.15 & 0.00 \\
\hline Toluene & 867 & 0.590 & 28.40 & 26.10 & 2.30 \\
\hline
\end{tabular}

\subsubsection{Calculations of solid surface energy}

Considering the values of contact angles of solid residues by liquids and basing on the Owens, Wendt and Rabel methods, calculations of solids surface energies were carried out according to the following equation [8]:

$$
\frac{\sigma_{l}(\cos \theta+1)}{2\left(\sigma_{I}^{D}\right)^{1 / 2}}=\left(\sigma_{s}^{P}\right)^{1 / 2} \cdot \frac{\left(\sigma_{l}^{P}\right)^{1 / 2}}{\left(\sigma_{I}^{D}\right)_{1 / 2}}+\left(\sigma_{s}^{D}\right)^{1 / 2}
$$

where $\sigma_{t}$ - surface tension of liquid; $\sigma_{s}$-surface energy of solid; $\sigma_{l}^{D}$-dispersive component for the surface tension of liquid; $\sigma_{s}^{D}$ - dispersive component for the surface energy of solid; $\sigma_{I}^{P}$ - polar component for the surface tension of liquid; $\sigma_{s}^{P}$ - polar component for the surface energy of solid; $\cos \theta$ - contact angle.

\subsubsection{M easurements of surface tension of liquids and liquid/ liquid interfacial tension}

Measurement component is a ring made of platinum- iridium alloy because of its high surface energy. By means of this method surface tension of liquids having known density can be measured.

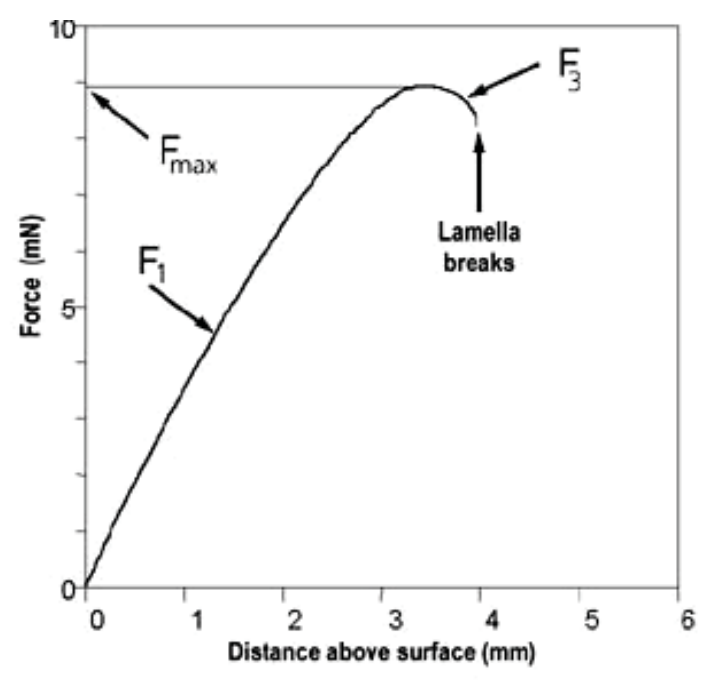

Fig. 5. Change of force with ring distance [6]
After a contact between measuring component and surface of the liquid, a measurement of forces acting on the weight system is started. Then the sample of the liquid is lowered, which causes the formation of liquid film below the ring. The liquid film is stretched during lowering of liquid sample. Surface tension is calculated according to the following equation:

$$
\sigma=\frac{F_{\max }-F_{V}}{L \cdot \cos \theta}
$$

where $\sigma$ - surface tension; $F_{\max }$ - maximum force; $F_{V}$ - weight of volume of lifted liquid; $L$ - wetted length; $\theta^{v}$ - contact angle [8].

The Harkins and Jordan correction method [9] is applied in the calculations. The principle of liquid/liquid interfacial tension measurement is the same as for liquid surface tension.

\subsubsection{Calculations of liquid surface tension components}

Basing on the dodecane/desulphurized vacuum residue interfacial tension and surface tension of liquids, components of surface tension of vacuum residue can be calculated using the Good's equation [10]:

$$
\gamma_{1,2}=\gamma_{1}+\gamma_{2}-2\left[\left(\gamma_{1}^{D} \gamma_{2}^{D}\right)^{1 / 2}+\left(\gamma_{1}^{P} \gamma_{2}^{P}\right)^{1 / 2}\right]
$$

where $\gamma_{1,2}$ - interfacial tension of liquid 1/ liquid 2; $\gamma_{1}$ - surface tension of liquid $1 ; \gamma_{2}$ - surface tension of liquid $2 ; \gamma_{1}^{D}$-dispersive component for the surface tension of liquid $1 ; \gamma_{2}{ }^{D}$ dispersive component for the surface tension of liquid $2 ; \gamma_{1}^{P}$ - polar component for the surface tension of liquid $1 ; \gamma_{2}^{P}-$ polar component for the surface tension of liquid 2.

From the Good's equation dispersion component of vacuum residue surface tension was determined and polar component from the relation of $\gamma_{1}=\gamma_{1}^{D}+\gamma_{1}^{P}$ was fixed.

\subsubsection{Polarity calculations of deposits and liquids}

Polarity is calculated as a contribution of polar component in total surface energy or surface tension [10]. 


$$
P_{s}=\frac{100 \cdot \gamma_{s}^{P}}{\gamma_{s}} P_{l}=\frac{100 \cdot \gamma_{I}^{P}}{\gamma_{1}}
$$

where $P$ - polarity, $\% ; \gamma_{1}-$ surface tension of liquid; $\gamma_{1}^{P}$ - polar component for the surface tension of liquid; $\gamma_{s}$ - surface energy of solid; $\gamma_{s}^{P}$ - polar component for the surface energy of solid.

\subsection{Flocculation point}

One of the approved methods of characterization of colloidal systems is based on the measurements of flocculation point of asphaltenes. It describes the volume of an reagent precipitating asphaltenes, which causes observable flocculation of dispersed phase. In this work the measurements of flocculation point of asphaltenes in studied samples of desulphurized vacuum residue were carried out using Hach 2100 AN turbidimeter.

The point marking the bend of linear dependence between scattered light intensity and volume of added $n$-heptane was accepted as asphaltene flocculation point [11].

In order to determine the flocculation point a titration of vacuum residue solutions in toluene with $n$-heptane was carried out. The investigations were conducted in room temperature in a measurement setup consisting of circulation pump, conical flask with burette and turbidimeter equipped with flow dish and sample temperature sensor.

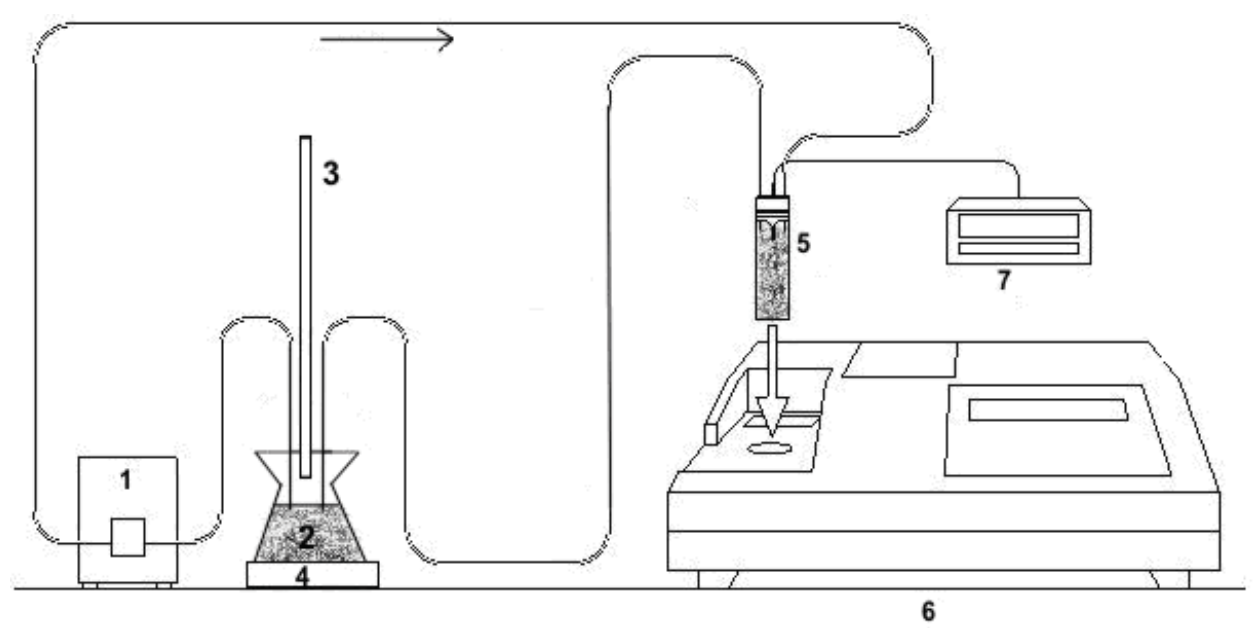

Fig. 6. Laboratory set for turbidimetric measurements in flow: 1 - peristaltic pump, 2 - Erlenmeyer conical flask with studied dispersion, 3 - burette, 4-magnetic stirrer, 5 - measurement dish, 6 - Hach 2100AN turbidimeter, 7 - temperature sensor

\subsection{Octel test}

By means of TurbiScan instrument produced by Formulaction, changes of dispersion state in time on different heights of immobilized sample can be studied. The instrument records the intensity of both transmitted and scattered light of studied sample at a given frequency.

In the way advised by the manual for the studies of petroleum residues, $2 \mathrm{ml}$ of $10 \%$ solution of desulphurized vacuum residue in toluene was added to $23 \mathrm{ml}$ of $n$-heptane. Immediate precipitation of asphaltene deposits was observed and recording of the results was started $[12,13]$.

\section{Results and Discussion}

\subsection{Compatibility of dispersion components}

Basing on the results of carried out studies we conclude that the increase of solvent's polarity increases the contact angle of a deposit. Applied (investigated) additives significantly improve the wettability of deposits by non-polar solvents. Additive K improves the wettability of deposits by non-polar solvents, but in the case of polar solvents the wettability increases insignificantly.

Surface energy of deposits was determined by means of Owens, Wendt and Rabel methods.

\section{Mass of $n$-heptane sorbed by a solid (powdered asphaltene deposit) and capillary constant of studied samples}

\begin{tabular}{|l|c|c|}
\hline \multicolumn{1}{|c|}{ Sample } & Mass, g & Capillary constant \\
\hline Solid & 0.7398 & $1.93 \cdot 10^{-5}$ \\
\hline Solid + additive A & 0.5056 & $2.12 \cdot 10^{-5}$ \\
\hline Solid + additive H & 0.6339 & $2.57 \cdot 10^{-5}$ \\
\hline Solid + additive K & 0.5427 & $1.93 \cdot 10^{-5}$ \\
\hline Solid + additive Z & 0.6801 & $2.59 \cdot 10^{-5}$ \\
\hline
\end{tabular}


Contact angles by different solvents

\begin{tabular}{|l|c|c|c|c|}
\hline \multirow{2}{*}{\multicolumn{1}{|c|}{ Sample }} & \multicolumn{4}{|c|}{ Contact angles by solvents, ${ }^{\circ}$} \\
\cline { 2 - 5 } & water & n-heptane & toluene & chloroform $^{-}$ \\
\hline Solid & 89.9 & 1.1 & 38.6 & 47.5 \\
\hline Solid + additive A & 87.3 & 1.2 & 90.0 & 53.3 \\
\hline Solid + additive H & 87.3 & 0.9 & 44.0 & 26.7 \\
\hline Solid + additive $K$ & 86.5 & 0.1 & 90.0 & 47.2 \\
\hline Solid + additive Z & 90.0 & 1.3 & 0.1 & 47.5 \\
\hline
\end{tabular}

Surface energy of deposits with division to components

\begin{tabular}{|l|c|c|c|}
\hline \multicolumn{1}{|c|}{ Sample } & $\begin{array}{c}\text { Surface } \\
\text { energy, } \\
\mathrm{mN} / \mathrm{m}\end{array}$ & $\begin{array}{c}\text { Dispersive } \\
\text { part,mN/m }\end{array}$ & $\begin{array}{c}\text { Polar part, } \\
\mathrm{mN} / \mathrm{m}\end{array}$ \\
\hline Solid & 24.3 & 18.5 & 5.8 \\
\hline Solid + additive $\mathrm{A}$ & 24.7 & 17.3 & 7.4 \\
\hline Solid + additive $\mathrm{H}$ & 26.5 & 20.6 & 5.9 \\
\hline Solid + additive $K$ & 20.6 & 10.4 & 10.2 \\
\hline Solid + additive $Z$ & 25.7 & 20.4 & 5.3 \\
\hline
\end{tabular}

Low value of polar component of surface energy indicates low polarity of the deposits surface (Fig. 7).

Table 5
Sur face tension with division to components

\begin{tabular}{|l|c|c|c|c|c|c|}
\hline \multicolumn{1}{|c|}{ Sample } & \multicolumn{2}{c|}{$\begin{array}{c}\text { Surface tension, } \\
\mathrm{mN} / \mathrm{m}\end{array}$} & \multicolumn{2}{c|}{$\begin{array}{c}\text { Dispersive part, } \\
\mathrm{mN} / \mathrm{m}\end{array}$} & \multicolumn{2}{c|}{$\begin{array}{c}\text { Polar part, } \\
\mathrm{mN} / \mathrm{m}\end{array}$} \\
\hline \multicolumn{1}{|c|}{ Concentration of additives, ppm } & 100 & 1000 & 100 & 1000 & 100 & 1000 \\
\hline Desulphurized vacuum residue & \multicolumn{2}{|c|}{27.35} & \multicolumn{2}{|c|}{25.60} & \multicolumn{2}{c|}{1.75} \\
\hline Desulphurized vacuum residue + additive A & 26.10 & 27.24 & 20.50 & 25.60 & 5.60 & 1.64 \\
\hline Desulphurized vacuum residue + additive H & 27.82 & 27.93 & 26.30 & 26.52 & 1.52 & 1.41 \\
\hline Desulphurized vacuum residue + additive $\mathrm{K}$ & 25.22 & 26.76 & 19.53 & 21.05 & 5.69 & 5.71 \\
\hline Desulphurized vacuum residue + additive Z & 27.72 & 27.93 & 26.05 & 26.60 & 1.67 & 1.43 \\
\hline
\end{tabular}

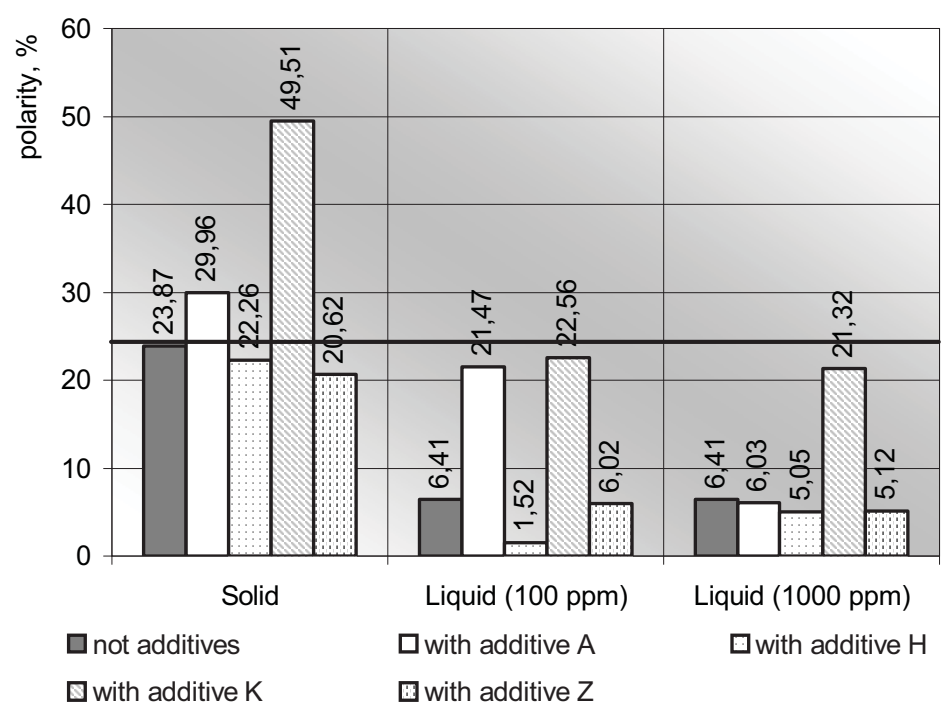

Fig. 7. Polarity of solid and liquid samples

Table 6 
When the difference between the polarity of a liquid and a solid is smaller, the components of the system are more compatible and the free energy of wetting value is lower. The percent of polarity indicates the quality of wettability and how the wettability can be changed by the modification of components, for instance, the modification of the solid surface in order to make its value closer to the polarity of a liquid. An example of the solid surface modification is a change of hydrophobic pigment towards higher polarity (hydrophilicity) in order to increase its dispersability in water. An example of the liquid modification is addition of a solvent to water in order to improve dispersibility of hydrophobic particles of low polarity.

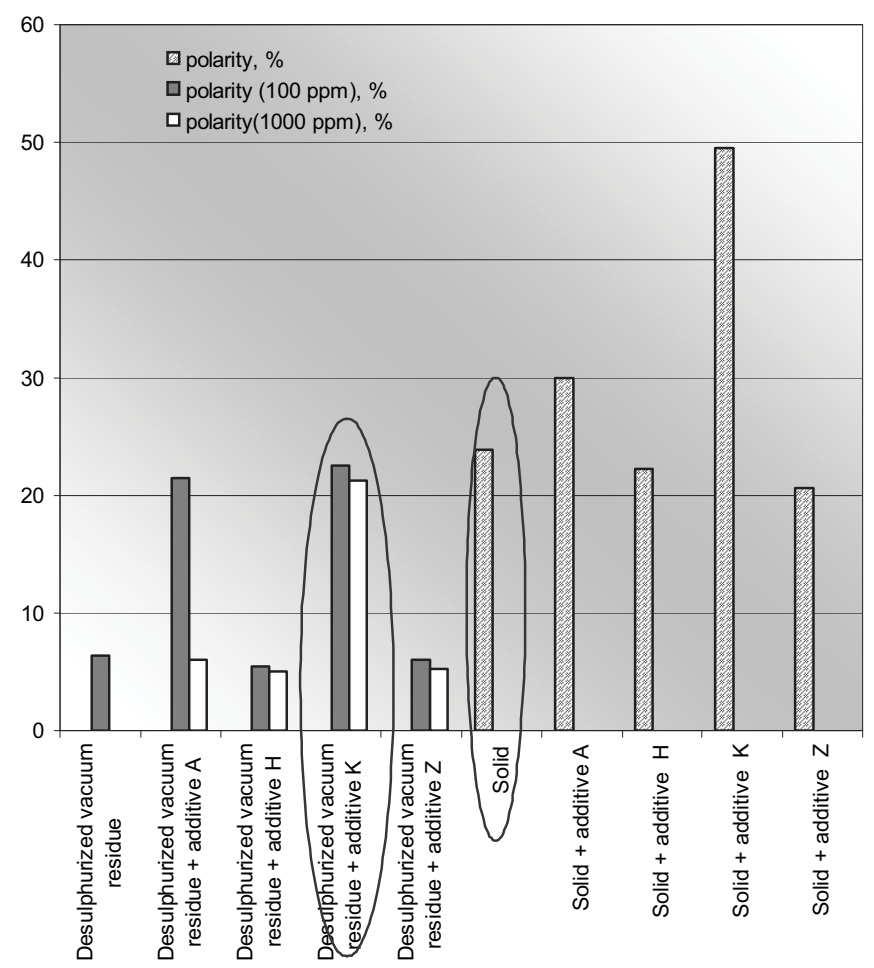

Basing on the experimental results it can be concluded that the deposits precipitating from desulphurized vacuum residue exhibit high polarity, much higher than the polarity of the liquid, which proves the termodynamical phase instability of desulphurized vacuum residue.

The most compatible systems consist of unmodified deposit and desulphurized vacuum residue modified with additive $\mathrm{K}$.

\subsection{Flocculation point}

The titration of vacuum residue solutions in toluene with $n$-heptane was carried out for the determination of flocculation point.

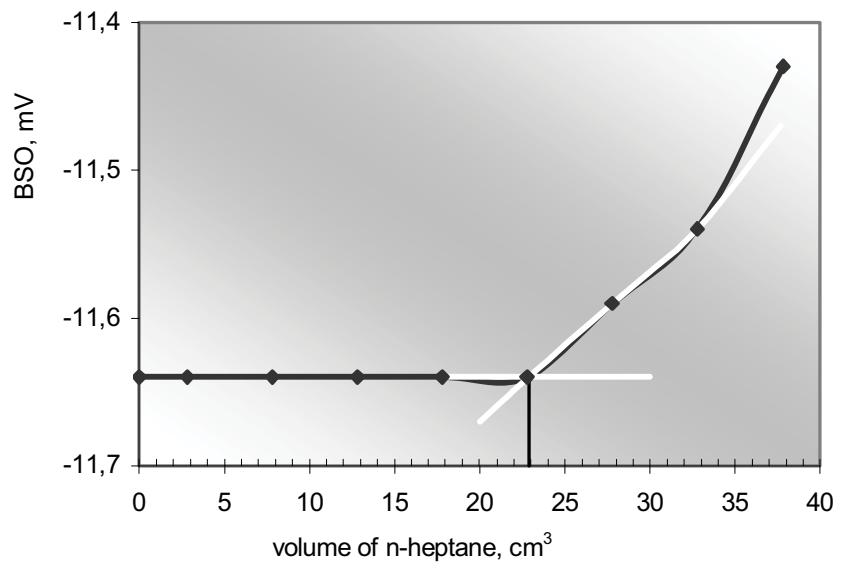

Fig. 9. Flocculation point of nonmodified solution of desulphurized vacuum residue

Fig. 8. Comparison of polarity of studied samples

Table 7

Flocculation point $\left(\mathrm{cm}^{3}, \mathrm{n}-\mathrm{C}_{7}\right)$ of asphaltenes in a solution of desulphurized vacuum residue in toluene and influence of dispersants used in concentrations of 100 and $1000 \mathrm{ppm}$

\begin{tabular}{|l|c|c|}
\hline \multirow{2}{*}{\multicolumn{1}{|c|}{ Sample }} & \multicolumn{2}{|c|}{$\begin{array}{c}\text { Concentrations of additives, } \\
\text { ppm }\end{array}$} \\
\cline { 2 - 3 } & 100 & 1000 \\
\hline Solution of desulphurized vacuum residue & 25 & 24 \\
\hline Solution of desulphurized vacuum residue + additive A & 22 & 22 \\
\hline Solution of desulphurized vacuum residue + additive Z & 29 & 26 \\
\hline Solution of desulphurized vacuum residue + additive $K$ & 26 & 24 \\
\hline Solution of desulphurized vacuum residue + additive H & \multicolumn{2}{|c|}{} \\
\hline
\end{tabular}


Basing on a single measurement of flocculation point of asphaltenes, full characterization of petroleum dispersion stability is not possible. However, it can be ascertained which studied sample exhibits higher resistance to flocculation and the direction of a modification of a given dispersion can be defined. The task of studied additives was the shift of the flocculation point towards higher volume of $n$-heptane causing the start of flocculation.
The highest improvement of asphaltene stability in a solution of desulphurized vacuum residue was observed when additive $K$ was applied. Slight improvement of stability was observed for $A$ and $H$ additives.

\subsection{Octel test}

The image of transmitted and backwards scattered light in so-called reference mode is presented in Fig. 10.

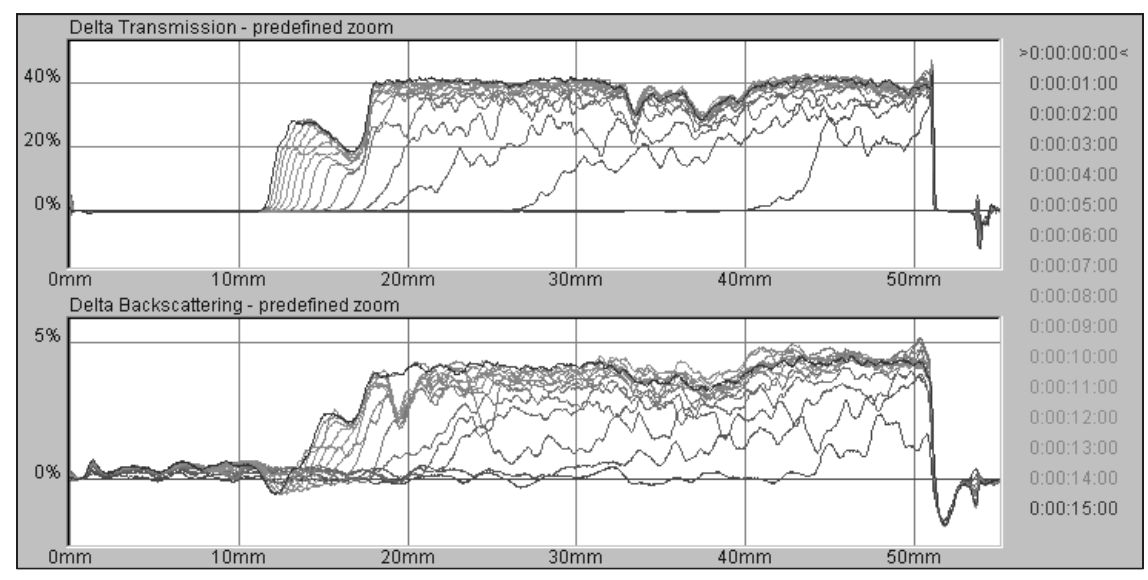

Fig. 10. The image of scanning turbidimetry of a solution of desulphurized vacuum residue

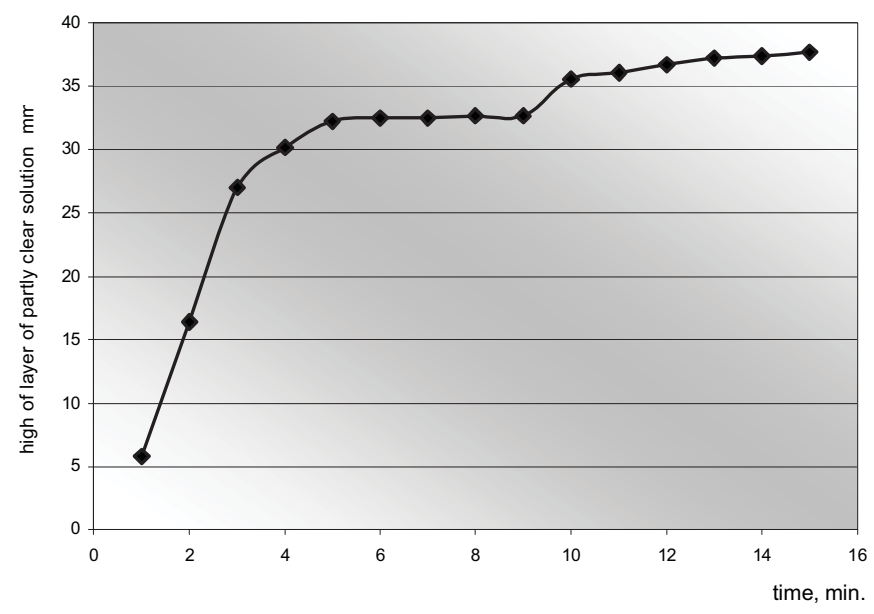

Fig. 11. Rate of clarification of desulphurized vacuum residue solution

Change of transmittance and the intensity of backwards scattered light for studied samples (45 $\mathrm{mm}$ layer)

\begin{tabular}{|l|c|c|c|c|}
\hline \multicolumn{1}{|c|}{ Sample } & \multicolumn{2}{c|}{ Change of transmittance, $\%$} & \multicolumn{2}{c|}{$\begin{array}{c}\text { Change of the intensity of } \\
\text { backwards scattered light, } \%\end{array}$} \\
\hline \multicolumn{1}{|c|}{ Concentration of additives, ppm } & 100 & 1000 & 100 & 1000 \\
\hline Solution of desulphurized vacuum residue & \multicolumn{2}{|c|}{40} & 5 & 7 \\
\hline $\begin{array}{l}\text { Solution of desulphurized vacuum residue + } \\
\text { additive A }\end{array}$ & 47 & 49 & 5 & 7 \\
\hline $\begin{array}{l}\text { Solution of desulphurized vacuum residue + } \\
\text { additive Z }\end{array}$ & 50 & 47 & 2 & 0.5 \\
\hline $\begin{array}{l}\text { Solution of desulphurized vacuum residue + } \\
\text { additive K }\end{array}$ & 12 & 16 & 7 & 1 \\
\hline $\begin{array}{l}\text { Solution of desulphurized vacuum residue + } \\
\text { additive H }\end{array}$ & 48 & & 5 \\
\hline
\end{tabular}

Table 8 
Sedimentation of dispersed phase (asphaltenes) takes place, which is depicted by rising (by $50 \mathrm{~mm}$ ) layer of partly clear solution. Transmittance of this layer reaches the value of about $40 \%$. It is accompanied by the intensity of backwards scattered light to a level of $5 \%$. At the same time the formation of deposit on the bottom of measurement dish is not observed. In the bottom part of the dish significant thickening of the dispersion occurs, and the rate of clear layer border is decreasing in time.

Basing on the experimental results it can be ascertained that the highest improvement of asphaltene stability in a solution of desulphurized vacuum residue is caused by the additive $K$. It is explained by strongly precipitating environment, in which a separate dispersed phase was formed and which does not sediment. It is proven by lower transmittance and intensity of backwards scattered light. Slight improvement of stability was observed for the $\mathrm{H}$ additive at high concentration.

\section{Conclusions}

Applied methods for evaluation of dispersion state and the directions of its modification using tensiometric and turbidibetric techniques seem to be an adequate tool for solving the problem.

Distillation residue - desulphurized vacuum residue is an unstable dispersion system. The instability is caused by:

- inadequate amount of petroleum resins (they are converted to a higher extent than asphaltenes);

- large differences in polarity of the components of the system.

Stabilization of the product is possible with the increase of dispersive ability of liquid phase and/or hydrophobization of asphaltene particles with surface active additives. Adequate improvement of dispersion stability is caused by the additive $\mathrm{K}$ applied at the concentration of $100 \mathrm{ppm}$.
Results of laboratory investigations await confirmation from the industrial tests at the vacuum residue hydrodesulphurization installation of PKN ORLEN S.A. refinery.

\section{References}

[1] Nowicki W. and Nowicka G.: Wiadomosci Chemiczne, 2001, 55,551 .

[2] Wandas R., Chrapek T., Tomasiewicz D. and Bielecki F.: [in:] Seminarium „Wspyiczesne wyzwania dla paliw silnikowych w Polsce", Piock 2001, 76.

[3] Chrapek T. and Wandas R.: Nafta Gaz, 1999, 11, 713.

[4] Lorek A. and Paczuski M.: Nafta Gaz, 2006, 9, 453.

[5] Lorek A. and Paczuski M.: Nafta Gaz, 2006, 3, 113.

[6] www.kruss.de

[7] Hiemenz P. C. and Rajagopalan R.: Principles of Colloid and Surface Chemistry. Marcel Dekker, New York 1997.

[8] Rulison C.: Kruss Technical Note \# 306, 2001.

[9] Harkins W. D. and Jordan F. J.: Colloid Int. Sci., 1930, 52, 1751.

[10] Rulison C.: Kruss Technical Note \# 213, 2001.

[11] www.hach.com

[12] Mengual O., Meunier G. et al.: Colloids and Surfaces A: Physicochemical and Engineering Aspects, 1999, 152, 11.

[13] Esumi K.: J. Colloid Interface Sci., 2001, 241, 1.

\section{ДОСЛІДЖЕННЯ СЕДИМЕНТАЦЇ̈ АСФАЛЬТЕНОВИХ ВІДКЛАДІВ У ДИСТИЛЯТНИХ ЗАЛИШКАХ}

Анотація. Наведено експериментальні методи оцінки стабільності твердих речовин у дисперсіях рідин. Для характеристики дисперсійних компонентів застосовували сучасні аналітичні методи, такі, як тензіометрія, сканування i статична турбідиметрія. Показаний вплив відібраних поверхнево-активних речовин на стабільність дисперсій.

Ключові слова: дисперсія, поверхневі властивості, стабільність, вакуумний залишок 
